\title{
Transfusion of Red Blood Cells Is Associated With Improved Central Venous Oxygen Saturation But Not Mortality in Septic Shock Patients
}

\author{
Farid Sadaka, ${ }^{\mathrm{a}, \mathrm{b}}$, Steven Trottier ${ }^{\mathrm{a}}$, David Tannehilla, Paige L Donnelly ${ }^{\mathrm{a}}$, Mia T Griffin ${ }^{\mathrm{a}}$, \\ Zerihun Bunaye $^{a}$, Jacklyn O'Brien ${ }^{\text {a }}$, Matthew Korobey ${ }^{a}$, Rekha Lakshmanan ${ }^{\mathrm{a}}$
}

\begin{abstract}
Background: Although the optimum hemoglobin $(\mathrm{H})$ concentration for patients with septic shock (SS) has not been specifically investigated, current guidelines suggest that $\mathrm{H}$ of $7-9 \mathrm{~g} / \mathrm{dL}$, compared with $10-12 \mathrm{~g} / \mathrm{dL}$, was not associated with increased mortality in critically ill adults. This contrasts with early goal-directed resuscitation protocols that use a target hematocrit of $30 \%$ in patients with low central venous oxygen saturation $\left(\mathrm{ScvO}_{2}\right)$ during the first 6 hours of resuscitation of SS.
\end{abstract}

Methods: Data elements were prospectively collected on all patients with SS patients (lactic acid (LA) $>4 \mathrm{mmol} / \mathrm{L}$, or hypotension). Out of a total of 396 SS patients, 46 patients received red blood cell (RBC) transfusion for $\mathrm{ScvO}_{2}<70 \%$ (RBC group). We then matched $71 \mathrm{SS}$ patients that did not receive $\mathrm{RBC}$ transfusion (NRBC group) on the following goals $(\mathrm{G})$ : LA obtained within 6 hours (G1), antibiotics given within 3 hours (G2), $20 \mathrm{~mL} / \mathrm{kg}$ fluid bolus followed by vasopressors (VP) if needed to keep mean arterial pressure $>65 \mathrm{~mm} \mathrm{Hg}(\mathrm{G} 3)$, central venous pressure $>8 \mathrm{~mm} \mathrm{Hg}$ within 6 hours (G4) and $\mathrm{ScvO}_{2}>70 \%$ within 6 hours (G5).

Results: In the RBC group, after one unit of RBC transfusion, $\mathrm{ScvO}_{2}$ improved from average of $63 \%( \pm 12 \%)$ to $68 \%( \pm 10 \%)$ $(\mathrm{P}=0.02)$. Sixteen patients required another unit of $\mathrm{RBC}$, and this resulted in increase of $\mathrm{ScvO}_{2}$ to $78 \%( \pm 11 \%)(\mathrm{P}<0.01)$. The $\mathrm{RBC}$ and NRBC groups were matched on sequential organ failure assessment (SOFA) scores and all five goals. There was no difference in mortality between the two groups: $41 \%$ vs. $39.4 \%$ (OR: $0.8,95 \%$ CI: $0.4-1.7, \mathrm{P}=0.6)$.

Conclusions: In our study, transfusion of RBC was not associated with decreased mortality in SS patients.

\footnotetext{
Manuscript accepted for publication May 5, 2014

${ }^{\mathrm{a}}$ Mercy Hospital St Louis; St Louis University, St. Louis, MO, USA

${ }^{\mathrm{b}}$ Corresponding Author: Farid Sadaka, St Louis University, $621 \mathrm{~S}$. New Ballas Rd, suite 4006B St. Louis, MO 63141, USA.

Email: farid.sadaka@mercy.net
}

doi: http://dx.doi.org/10.14740/jocmr1843w
Keywords: RBC; Transfusion; Septic shock; EGDT; Early goal-directed therapy; Mortality; $\mathrm{ScvO}_{2}$; Central venous oxygen saturation

\section{Introduction}

In the United States, approximately 750,000 cases of sepsis occur each year, of which at least 225,000 are fatal. If it also causes organ dysfunction, the diagnosis is severe sepsis. If severe sepsis is accompanied with tissue hypoperfusion, the diagnosis is septic shock (SS). Organ failure occurs in about one-third of patients with sepsis, and severe sepsis is associated with an estimated mortality rate of $30-50 \%$. There is wide variation in the incidence of sepsis and severe sepsis in the intensive care unit (ICU) setting, with reported rates ranging from $20 \%$ to $80 \%$, and reported mortality of $20 \%$ to $50 \%$. SS, defined as a state of acute circulatory failure characterized by persistent hypotension unexplained by other causes, despite adequate fluid resuscitation, affects between $10 \%$ and $30 \%$ of patients managed in the ICU, and its incidence is increasing. Mortality from SS in the ICU is estimated to range between $45 \%$ and $63 \%$ in observational studies [1-7].

Guidelines published as part of the surviving sepsis campaign (SSC) [8] have endorsed use of red blood cells (RBCs) in the treatment of patients with severe sepsis and SS who show evidence of hypoperfusion. This recommendation is primarily based on studies that evaluated a bundle approach to patients in severe sepsis [9]. RBC transfusion to obtain a hematocrit of $30 \%$ is included in this bundle for patients with a central venous oxygen saturation $\left(\mathrm{ScvO}_{2}\right)<$ $70 \%$. Patients achieving this goal had better outcomes than patients who did not reach the goal. The specific effect of transfusion was not evaluated in this study, however, as the investigation was designed to assess the overall bundle rather than its component parts. On the other hand, several studies, summarized in literature [10] point to several problems documented with RBC transfusions, such as infection, pulmonary complications such as transfusion-related acute lung injury, fluid overload, transfusion-related immunomodulation, multiorgan failure and increased mortality. As a 


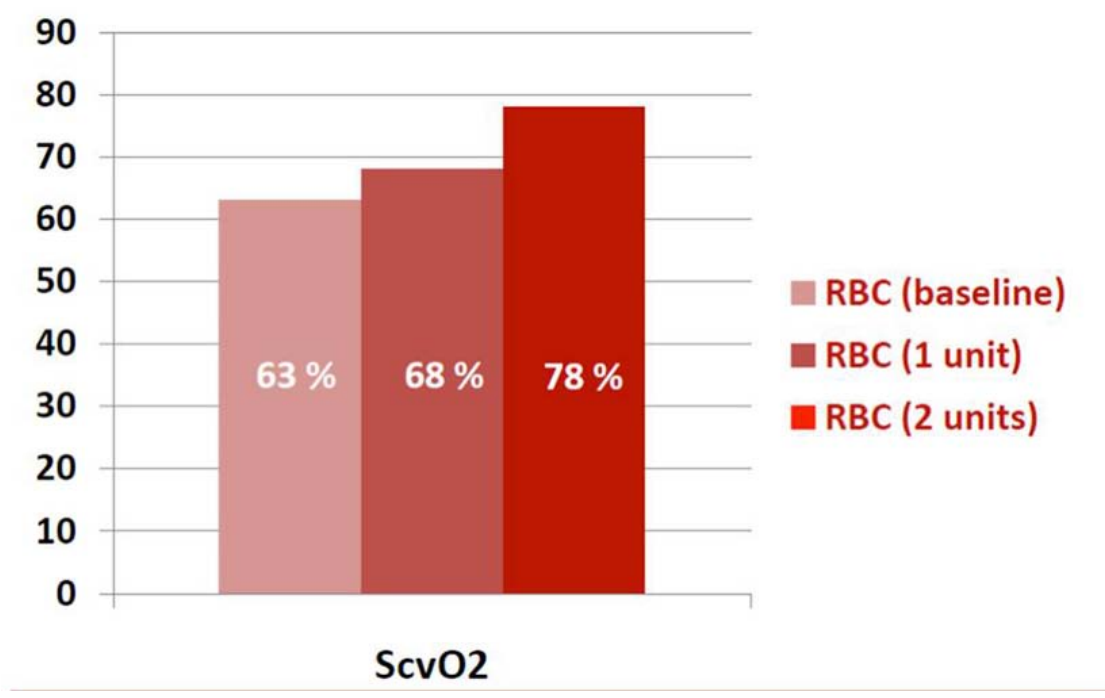

Figure 1. $\mathrm{ScvO}_{2}$ values after one and two units in the RBC group.

result, outside this window during the first $6 \mathrm{~h}$ of early-goal directed therapy (EGDT) for severe sepsis and SS, a "restrictive" strategy of RBC transfusion (transfuse when $\mathrm{Hb}<7 \mathrm{~g}$ / $\mathrm{dL})$ is recommended.

The primary objective of this study is to evaluate the effect of RBC transfusion on $\mathrm{ScvO}_{2}$ and mortality when used during EGDT for patients with SS.

\section{Methods}

As discussed above, following SSC guidelines with rapid recognition and aggressive intervention of SS dramatically improves outcome. As a result, a sepsis team has been created in our institution in order to increase compliance with SSC guidelines. As soon as an SS patient is identified anywhere in the hospital, the sepsis team is called to go to the bedside and initiate EGDT. Data are prospectively collected on these patients in order to examine the effectiveness of this effort and its impact on improving compliance with the EGDT bundle and outcomes. As a result, data elements were prospectively collected on all patients. This study is a retrospective review of this database.

SS patients (defined as lactic acid (LA) $>4 \mathrm{mmol} / \mathrm{L}$, or hypotension persistent after initial fluid challenge) admitted between June 2011 and March 2013 were included. We identified a total of $396 \mathrm{SS}$ patients. The protocol was as follows: As soon as a patient was diagnosed with sepsis and sepsis team is notified, an LA was measured. Once patient is diagnosed with SS, a $20 \mathrm{~mL} / \mathrm{kg}$ bolus of crystalloid was given to achieve a central venous pressure of $8-12 \mathrm{~mm} \mathrm{Hg}$. If the mean arterial pressure was less than $65 \mathrm{~mm} \mathrm{Hg}$, vasopressors were given to maintain a mean arterial pressure of at least 65 $\mathrm{mm} \mathrm{Hg}$. Once these goals are achieved, if the central venous oxygen saturation was less than $70 \%$, RBCs were transfused to achieve a hematocrit of at least $30 \%$.

Forty-six patients received RBC transfusion for $\mathrm{ScvO}_{2}$ $<70 \%$ (RBC group). Of the remaining patients, we then matched 71 SS patients that did not receive RBC transfusion (NRBC group) on the following goals (G) based on SSC 2008 criteria [11]: LA obtained within $6 \mathrm{~h}$ (G1), antibiotics given within $3 \mathrm{~h}(\mathrm{G} 2), 20 \mathrm{~mL} / \mathrm{kg}$ fluid bolus followed by vasopressors (VP) if needed to keep mean arterial pressure (MAP) $>65 \mathrm{~mm} \mathrm{Hg}(\mathrm{G} 3)$, central venous pressure (CVP) $\geq 8 \mathrm{~mm} \mathrm{Hg}$ within $6 \mathrm{~h}(\mathrm{G} 4)$ and $\mathrm{ScvO}_{2} \geq 70 \%$ within $6 \mathrm{~h}$ (G5). We calculated average age, average sequential organ failure assessment (SOFA) scores and fluid balance at the end of $6 \mathrm{~h}$ for both groups. In the RBC group, we collected $\mathrm{ScvO}_{2}$ levels before and after each unit of RBC transfused. Outcome was hospital mortality. Matching is used to evaluate the effect of a treatment by comparing the treated and the non-treated patients in an observational study (especially when the treatment is not randomly assigned). The goal of matching is for every treated patient, to find one non-treated patient (in this case transfusion versus no transfusion) with similar observable characteristics against whom the effect of treatment can be assessed. By matching treated patients to similar non-treated patients, matching enables a comparison of outcomes in order to estimate the effect of the treatment without reduced bias due to confounding. In this case, all of the goals (G1-G5) could confound outcome and thus were all matched. The RBC and NRBC groups were compared by Pearson Chi-squared and Fisher's exact tests to analyze statistical significance. Mean, standard deviation and $P$ value were reported for each comparison. Statistical significance was defined as $\mathrm{P} \leq 0.05$. This study was approved by Mercy 
Table 1. Characteristics of RBC and NRBC Groups With Septic Shock

\begin{tabular}{llll}
\hline & RBC & NRBC & P value \\
\hline $\mathrm{N}$ & 46 & 71 & 0.06 \\
Age, mean, SD & $71(15)$ & $65(17)$ & 0.8 \\
SOFA score, mean, SD & $8.6(3.9)$ & $8.4(3.4)$ & 0.2 \\
Fluid balance at 6 h, mL, mean, SD & $3,500(1,700)$ & $4,000(2,100)$ & 0.4 \\
Lactic acid & $4.4( \pm 3.9)$ & $3.9( \pm 2.8)$ & 0.5 \\
Vasopressors, n, \% & $29(63 \%)$ & $40(56 \%)$ & 0.6 \\
LA within 6 h, n, \% (G1) & $43(93 \%)$ & $68(96 \%)$ & 0.2 \\
Antibiotics with 3 h, n, \% (G2) & $31(67 \%)$ & $40(56 \%)$ & 0.6 \\
20 mL/kg, then vasopressors, n, \%(G3) & $35(76 \%)$ & $57(80 \%)$ & 0.5 \\
CVP $\geq 8$ mm Hg within 6 h, n, \% (G4) & $21(46 \%)$ & $29(41 \%)$ & 0.9 \\
ScvO $\geq 70 \%$ within 6 h, n, \% (G5) & $12(26 \%)$ & $19(27 \%)$ & \\
\hline
\end{tabular}

Hospital Institutional Review Board.

\section{Results}

In the $\mathrm{RBC}$ group, after one unit of $\mathrm{RBC}$ transfusion, $\mathrm{ScvO}$ improved from average of $63 \%( \pm 12 \%)$ to $68 \%( \pm 10 \%)(\mathrm{P}$ $=0.02)$. Sixteen patients required another unit of RBC, and this resulted in increase of $\mathrm{ScvO}_{2}$ to $78 \%( \pm 11 \%)(\mathrm{P}<0.01)$ (Fig. 1). All these transfusions were for $\mathrm{ScvO}_{2}<70 \%$ as part of EGDT. None of the transfusions were for other indications, such as bleeding, hemolysis, or bone marrow dyscrasias. Although all patients in the RBC group got transfused, not all of them achieved this goal $\left(\mathrm{ScvO}_{2} \geq 70 \%\right)$ at the $6 \mathrm{~h}$ mark, which explains the findings in Table 1.

The two groups were matched on age and severity of illness. For the RBC group and NRBC group respectively, age in years was $71( \pm 15)$ vs. $65.9( \pm 17)(\mathrm{P}=0.06)$, and SOFA score $8.6( \pm 3.9)$ vs. $8.4( \pm 3.4)(\mathrm{P}=0.8)$. The $\mathrm{RBC}$ and NRBC groups were also matched on goals of resuscitation as follows: fluid balance in $\mathrm{mL}$ at $6 \mathrm{~h}$ was $3,500( \pm 1,700) \mathrm{vs}$. $4,000( \pm 2,100)(\mathrm{P}=0.2)$. LA was $4.4( \pm 3.9)$ vs. $3.9( \pm 2.8)$ $(\mathrm{P}=0.4)$, VPs were used in $29(63 \%)$ vs. 40 patients $(56 \%)$ $(\mathrm{P}=0.5)$, the goal of obtaining LA within $6 \mathrm{~h}$ was achieved in $43(93 \%)$ vs. 68 patients $(96 \%)(\mathrm{P}=0.6)$, the goal of giving antibiotics within $3 \mathrm{~h}$ was achieved in $31(67 \%)$ vs. 40 patients $(56 \%)(\mathrm{P}=0.2)$, the goal of achieving MAP $>65$ with fluid and VP was achieved in $35(76 \%)$ vs. 57 patients $(80 \%)(\mathrm{P}=0.6)$, CVP goal was achieved within $6 \mathrm{~h}$ in 21 $(46 \%)$ vs. 29 patients $(41 \%)(\mathrm{P}=0.5)$ and $\mathrm{ScvO}_{2}$ goal was achieved within $6 \mathrm{~h}$ in $12(26 \%)$ vs. 19 patients $(27 \%)(\mathrm{P}=$
0.9) (Table 1). There was no difference in mortality between the two groups: $41 \%$ vs. $39.4 \%$ (OR: $0.8 ; 95 \%$ CI: $0.4-1.7$, $\mathrm{P}=0.6$ ) (Fig. 2).

\section{Discussion}

RBC transfusion is one of the most commonly used interventions in the ICU to treat severe anemia, which often occurs in SS. In the United States, more than 14 million units of RBCs are administered annually, many of which are administered in the ICU and in SS patients [12]. Approximately 40-80\% of RBC transfusions are not given for bleeding, but rather for low hemoglobin levels, for a decrease in physiological reserve, or for alterations in tissue perfusion [13, 14]. Forty to fifty percent of septic and other critically ill patients require blood transfusion during their ICU stay [15]. By day two in the ICU, nearly $95 \%$ of patients are anemic [13].

For years, it was considered that a hemoglobin concentration of $10 \mathrm{~g} / \mathrm{dL}$, or a hematocrit of $30 \%$, represented the lowest level acceptable, thereby providing a standard and convenient "transfusion trigger" [16]. This was adopted based on the fact that tissue oxygen delivery $\left(\mathrm{DO}_{2}\right)$ is the product of tissue blood flow and arterial oxygen content. Tissue blood flow is thus determined by cardiac output and regional vasoregulation, and arterial oxygen content depends on hemoglobin concentration and its percentage saturation. Oxygen flow increases as the hemoglobin falls to a level termed the "optimal hematocrit", at which point $\mathrm{DO}_{2}$ is highest at the lowest energy cost to the individual. This occurs around a hematocrit of 30\% [17]. Below this "optimal" 


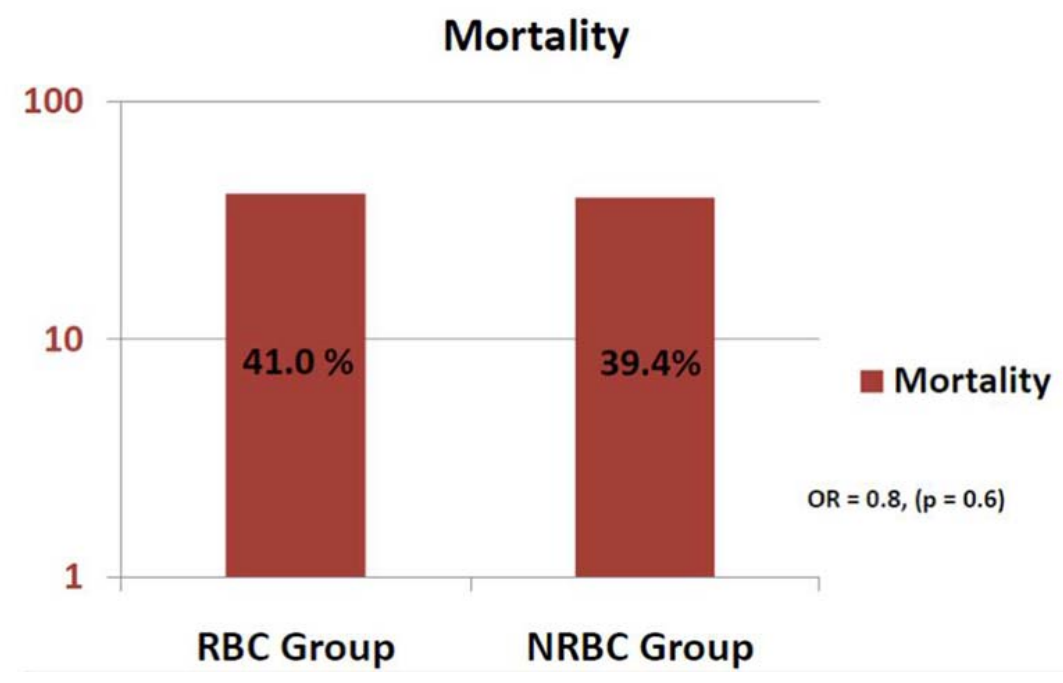

Figure 2. Hospital mortality of the RBC and NRBC groups.

level, the maintenance of tissue oxygen consumption $\left(\mathrm{VO}_{2}\right)$ and aerobic metabolism at decreasing levels of $\mathrm{DO}_{2}$ is principally provided by increased oxygen extraction. In the critical care environment, there have been several studies examining the interrelationship between hematocrit, $\mathrm{DO}_{2}$ and $\mathrm{VO}_{2}$. Shoemaker et al [18] and Boyd et al [19] initially defined the optimal hematocrit at around $30 \%$ since, below this level, oxygen delivery and consumption were decreased in critically ill patients and mortality was increased. Above this level, there was no change in these variables or outcome. This line of reasoning led to the common practice of maintaining this "10/30 rule" as the transfusion trigger. Subsequently, several problems were documented with RBC transfusions, such as infection, pulmonary complications such as TRALI and transfusion-associated circulatory overload (TACO), transfusion-related immunomodulation (TRIM) and multiorgan failure, and increased mortality [20]. This lead to the need for evaluation of restrictive transfusion strategies.

The best evidence available regarding the efficacy of $\mathrm{RBC}$ transfusion among critically ill patients including SS is from a randomized controlled trial, the transfusion requirements in critical care (TRICC) trial, conducted by the Canadian Critical Care Trials Group [21]. In this study, a liberal transfusion strategy (hemoglobin $10-12 \mathrm{~g} / \mathrm{dL}$, with a transfusion trigger of $10 \mathrm{~g} / \mathrm{dL}$ ) was compared to a restrictive transfusion strategy (hemoglobin $7-9 \mathrm{~g} / \mathrm{dL}$, with a transfusion trigger of $7 \mathrm{~g} / \mathrm{dL}$ ) in a general medical and surgical critical care population. Patients who were euvolemic after initial treatment who had a hemoglobin concentration $<9 \mathrm{~g} /$ $\mathrm{dL}$ within $72 \mathrm{~h}$ were enrolled. The TRICC trial documented an overall nonsignificant trend toward decreased 30-day mortality in the restrictive group; however, there was a significant decrease in mortality in the restrictive group among patients who were less acutely ill (APACHE II scores < 20) and among younger patients ( $<55$ years of age). Patients in the restrictive group received $54 \%$ less $\mathrm{RBC}$ units than those in the liberal group [21]. The diversity of patients enrolled in the trial and the consistency of the results suggest that the conclusions may be generalized to most critical care patients including SS patients. In a recent analysis by the Cochrane database of 19 trials involving a total of 6,264 patients, restrictive transfusion strategies were associated with a statistically significant reduction in hospital mortality (RR: 0.77 , $95 \%$ CI: $0.62-0.95$ ) but not 30-day mortality (RR: 0.85 , $95 \%$ CI: $0.70-1.03$ ) [22]. The authors concluded that the existing evidence supports the use of restrictive transfusion triggers in most patients including those with pre-existing cardiovascular disease.

Guidelines published as part of the SSC [8] have endorsed use of RBCs in the treatment of patients with severe sepsis and SS who show evidence of hypoperfusion. EGDT thus calls for an increase in hematocrit to at least 30\% in the setting of perceived oxygen deficit. The specific effect of transfusion was not evaluated in this study, however, as the investigation was designed to assess the overall bundle rather than its component parts. The pathologic effects of RBC transfusion in sepsis could be numerous. Several studies have demonstrated that RBC rheology is impaired (increased aggregation, decreased deformability, alterations of $\mathrm{RBC}$ shape) in recipient RBCs in SS patients [23-26]. RBC can also act as oxygen sensor, which can modulate tissue oxygen flow variables, by the release of the vasodilators, nitric oxide [27, 28] or ATP [29]. This release of vasodilators from RBCs during hypoxia could be impaired during storage and/or sepsis/septic shock. Storage of RBCs decreases levels of 2,3-diphosphoglycerate and adenosine triphosphate 
(ATP) levels with a resultant increase in oxygen affinity and a decrease in the ability of hemoglobin to offload oxygen. Morphological changes in erythrocytes occur during storage which may result in increased fragility, decreased viability and decreased deformability of RBCs. A release of a number of substances occurs during storage resulting in such adverse systemic responses as fever, cellular injury, alterations in regional and global blood flow, and organ dysfunction. Using near infrared spectroscopy (NIRS) or sidestream dark field (SDF), several investigators have reported that microcirculation is markedly altered in sepsis, that these alterations are more severe in nonsurvivors than in survivors, that persistent microvascular alterations are associated with development of multiple organ failure and death and that microvascular alterations are the most sensitive and specific predictor of outcome in septic patients [30-34]. In severe septic patient requiring leukoreduced RBC transfusion, using sidestream dark field (SDF), Sakr et al showed that the sublingual microcirculation was globally unaltered; however, it improved in patients with altered capillary perfusion at baseline [35]. Using both SDF and NIRS, Sadaka et al looked at patients that got non-leukoreduced RBCs for a hemoglobin $<7.0$, or for a hemoglobin between 7.0 and 9.0 with either lactic acidosis or central venous oxygen saturation $<70 \%$ [36]. Sadaka et al showed that muscle tissue oxygen consumption, microvascular reactivity and sublingual microcirculation were globally unaltered by RBC transfusion in severe septic and SS patients. However, muscle oxygen consumption improved in patients with low baseline and deteriorated in patients with preserved baseline [36]. In this study, we showed that transfusion of RBC during the EGDT period of resuscitation of SS was not associated with decreased mortality, despite improvement of $\mathrm{ScvO}_{2}$ values. Improvement in oxygen delivery with RBC transfusion could have been offset by the multiple pathophysiologic effects of transfusing RBCs. Given the clinical evidence and the aforementioned pathophysiologic alterations associated with RBCs, our findings are thus not surprising and further question the rationale of transfusion during EGDT for SS patients.

Our study has several limitations. The small sample size is an obvious limitation. Although we prospectively collected robust data and accounted for bundle compliance data during EGDT, we still cannot exclude the possibility of unaccounted, unmatched or missing data, which may lead to bias and undetected differences in baseline characteristics. In addition, there may be unaccounted differences in treatment of the patients in the two groups, which can lead to differences in outcomes. Although the two groups were matched on basic characteristics and goals of EGDT, exact matching remains challenging due to the retrospective nature of the study, the small number of patients, and the inability to match on baseline hematocrit and $\mathrm{ScvO}_{2}$ levels which lead to one group ( $\mathrm{RBC}$ group) getting transfused and not the other group (NRBC group). However, patients are closely matched on severity of illness as apparent by nonsignificant difference in SOFA scores between the two groups. Another limitation is lack of multivariate analysis that was not used due to the small number of patients. By the same token, a power analysis was not undertaken since this is a retrospective review of data and thus the results of this study are considered hypothesis generating and not conclusive. All this makes drawing final conclusions difficult based on findings of this trial alone.

\section{Conclusion}

In our study, transfusion of RBC was not associated with decreased mortality in SS patients, despite improvement in $\mathrm{ScvO}_{2}$ values. This and other studies mentioned above raise a concern about liberal transfusion during resuscitation phase of SS patients. This study does suggest that better means of identifying a need for transfusion are needed and that blindly transfusing to an arbitrarily set (and high) $\mathrm{Hb}$ may be detrimental. Future research with larger samples is needed to further examine the association between RBC transfusion and outcomes of patients resuscitated early in SS.

\section{Acknowledgement}

None.

\section{Sponsorship and Disclosures}

This study was not sponsored. None of the authors have anything to disclose.

\section{References}

1. Martin GS, Mannino DM, Eaton S, Moss M. The epidemiology of sepsis in the United States from 1979 through 2000. N Engl J Med. 2003;348(16):1546-1554.

2. Brun-Buisson C, Doyon F, Carlet J, Dellamonica P, Gouin F, Lepoutre A, Mercier JC, et al. Incidence, risk factors, and outcome of severe sepsis and septic shock in adults. A multicenter prospective study in intensive care units. French ICU Group for Severe Sepsis. JAMA. 1995;274(12):968-974.

3. Karlsson S, Ruokonen E, Varpula T, Ala-Kokko TI, Pettila V. Long-term outcome and quality-adjusted life years after severe sepsis. Crit Care Med. 2009;37(4):1268-1274.

4. Angus DC, Linde-Zwirble WT, Lidicker J, Clermont G, Carcillo J, Pinsky MR. Epidemiology of severe sepsis in the United States: analysis of incidence, outcome, and associated costs of care. Crit Care Med. 2001;29(7):13031310 . 
5. Annane D, Aegerter P, Jars-Guincestre MC, Guidet B. Current epidemiology of septic shock: the CUB-Rea Network. Am J Respir Crit Care Med. 2003;168(2):165172.

6. Pittet D, Rangel-Frausto S, Li N, Tarara D, Costigan M, Rempe L, Jebson P, et al. Systemic inflammatory response syndrome, sepsis, severe sepsis and septic shock: incidence, morbidities and outcomes in surgical ICU patients. Intensive Care Med. 1995;21(4):302-309.

7. Quenot JP, Binquet C, Kara F, Martinet O, Ganster F, Navellou JC, Castelain V, et al. The epidemiology of septic shock in French intensive care units: the prospective multicenter cohort EPISS study. Crit Care. 2013;17(2):R65.

8. Dellinger RP, Levy MM, Rhodes A, Annane D, Gerlach H, Opal SM, Sevransky JE, et al. Surviving sepsis campaign: international guidelines for management of severe sepsis and septic shock: 2012. Crit Care Med. 2013;41(2):580-637.

9. Rivers E, Nguyen B, Havstad S, Ressler J, Muzzin A, Knoblich B, Peterson E, et al. Early goal-directed therapy in the treatment of severe sepsis and septic shock. N Engl J Med. 2001;345(19):1368-1377.

10. Napolitano LM, Kurek S, Luchette FA, Corwin HL, Barie PS, Tisherman SA, Hebert PC, et al. Clinical practice guideline: red blood cell transfusion in adult trauma and critical care. Crit Care Med. 2009;37(12):3124-3157.

11. Dellinger RP, Levy MM, Carlet JM, Bion J, Parker MM, Jaeschke R, Reinhart K, et al. Surviving Sepsis Campaign: international guidelines for management of severe sepsis and septic shock: 2008. Crit Care Med. 2008;36(1):296-327.

12. Comprehensive report on blood collection and transfusion in the US in 2001. Available online at: www.nbdrc. org.

13. Vincent JL, Baron JF, Reinhart K, Gattinoni L, Thijs L, Webb A, Meier-Hellmann A, et al. Anemia and blood transfusion in critically ill patients. JAMA. 2002;288(12):1499-1507.

14. Corwin HL, Gettinger A, Pearl RG, Fink MP, Levy MM, Abraham E, MacIntyre NR, et al. The CRIT Study: Anemia and blood transfusion in the critically ill--current clinical practice in the United States. Crit Care Med. 2004;32(1):39-52.

15. Brown RB, Klar J, Teres D, Lemeshow S, Sands M. Prospective study of clinical bleeding in intensive care unit patients. Crit Care Med. 1988;16(12):1171-1176.

16. Zauder HL. Preoperative hemoglobin requirements. Anesth Clin North Am. 1990;8:471-480.

17. Messmer K, Lewis DH, Sunder-Plassmann L, Klovekorn WP, Mendler N, Holper K. Acute normovolemic hemodilution. Changes of central hemodynamics and microcirculatory flow in skeletal muscle. Eur Surg Res. 1972;4(1):55-70.
18. Shoemaker WC, Appel PL, Kram HB, Waxman K, Lee TS. Prospective trial of supranormal values of survivors as therapeutic goals in high-risk surgical patients. Chest. 1988;94(6):1176-1186.

19. Boyd O, Grounds RM, Bennett ED. A randomized clinical trial of the effect of deliberate perioperative increase of oxygen delivery on mortality in high-risk surgical patients. JAMA. 1993;270(22):2699-2707.

20. Sadaka F. Red Blood Cell Transfusion in Sepsis: A Review. J Blood Disord Transfus. 2012;S4:001.

21. Hebert PC, Wells G, Blajchman MA, Marshall J, Martin C, Pagliarello G, Tweeddale M, et al. A multicenter, randomized, controlled clinical trial of transfusion requirements in critical care. Transfusion Requirements in Critical Care Investigators, Canadian Critical Care Trials Group. N Engl J Med. 1999;340(6):409-417.

22. Carson JL, Carless PA, Hebert PC. Transfusion thresholds and other strategies for guiding allogeneic red blood cell transfusion. Cochrane Database Syst Rev. 2012;4:CD002042.

23. Powell RJ, Machiedo GW, Rush BF, Jr. Decreased red blood cell deformability and impaired oxygen utilization during human sepsis. Am Surg. 1993;59(1):65-68.

24. Baskurt OK, Gelmont D, Meiselman HJ. Red blood cell deformability in sepsis. Am J Respir Crit Care Med. 1998;157(2):421-427.

25. Reggiori G, Occhipinti G, De Gasperi A, Vincent JL, Piagnerelli M. Early alterations of red blood cell rheology in critically ill patients. Crit Care Med. 2009;37(12):3041-3046.

26. Hurd TC, Dasmahapatra KS, Rush BF, Jr., Machiedo GW. Red blood cell deformability in human and experimental sepsis. Arch Surg. 1988;123(2):217-220.

27. Cosby K, Partovi KS, Crawford JH, Patel RP, Reiter CD, Martyr S, Yang BK, et al. Nitrite reduction to nitric oxide by deoxyhemoglobin vasodilates the human circulation. Nat Med. 2003;9(12):1498-1505.

28. Jia L, Bonaventura C, Bonaventura J, Stamler JS. S-nitrosohaemoglobin: a dynamic activity of blood involved in vascular control. Nature. 1996;380(6571):221-226.

29. Ellsworth ML. The red blood cell as an oxygen sensor: what is the evidence? Acta Physiol Scand. 2000;168(4):551-559.

30. De Backer D, Creteur J, Preiser JC, Dubois MJ, Vincent JL. Microvascular blood flow is altered in patients with sepsis. Am J Respir Crit Care Med. 2002;166(1):98-104.

31. Trzeciak S, Dellinger RP, Parrillo JE, Guglielmi M, Bajaj J, Abate NL, Arnold RC, et al. Early microcirculatory perfusion derangements in patients with severe sepsis and septic shock: relationship to hemodynamics, oxygen transport, and survival. Ann Emerg Med. 2007;49(1):8898, 98 e81-82.

32. Sakr Y, Dubois MJ, De Backer D, Creteur J, Vincent JL. Persistent microcirculatory alterations are associ- 
ated with organ failure and death in patients with septic shock. Crit Care Med. 2004;32(9):1825-1831.

33. Pareznik R, Knezevic R, Voga G, Podbregar M. Changes in muscle tissue oxygenation during stagnant ischemia in septic patients. Intensive Care Med. 2006;32(1):8792.

34. Creteur J, Carollo T, Soldati G, Buchele G, De Backer $\mathrm{D}$, Vincent JL. The prognostic value of muscle $\mathrm{StO} 2$ in septic patients. Intensive Care Med. 2007;33(9):1549-
1556.

35. Sakr Y, Chierego M, Piagnerelli M, Verdant C, Dubois MJ, Koch M, Creteur J, et al. Microvascular response to red blood cell transfusion in patients with severe sepsis. Crit Care Med. 2007;35(7):1639-1644.

36. Sadaka F, Aggu-Sher R, Krause K, O’Brien J, Armbrecht ES, Taylor RW. The effect of red blood cell transfusion on tissue oxygenation and microcirculation in severe septic patients. Ann Intensive Care. 2011;1(1):46. 